\title{
ANALISA BEBAN TRANSFORMATOR DISTRIBUSI 3 FASA PADA PENYULANG 1 PT. PLN (PERSERO) ULK TARAKAN
}

\author{
Achmad Budiman ${ }^{1}$, Andi Munair ${ }^{2}$ \\ ${ }^{1,2}$ Universitas Borneo Tarakan, Tarakan, Kalimantan Utara, Indonesia \\ ${ }^{1}$ achmad1177@gmail. com \\ ${ }^{2}$ munaerr_je@gmail.com
}

\begin{abstract}
In the distribution of electrical energy to customers, sometimes not all of the energy generated reaches the customer due to losses incurred in the transformer. In this study the authors conducted a focused analysis on the 3 phase distribution transformer on feeder 1 located at PT. PLN (Persero) ULK Tarakan to determine the effect of the unbalanced 3 phase distribution transformer load on current, power losses and transformer efficiency. From the results of the calculation of data analysis that of the 38 transformers that can be said to be balanced that still meet the IEEE standard requirements there are 19 transformers for the morning and 12 transformers for the evening. While that can be said to be unbalanced that does not meet IEEE standards there are 19 transformers for the morning and 26 transformers for the evening. Efficiency will be greater if the incoming power and the outgoing power does not have a large difference or efficiency will be greater if the losses (losses) power is getting smaller but vice versa. Power losses due to neutral currents flowing in neutral conductors can be reduced if the cross-sectional area is enlarged, but a large cost is required. Keywords-3 phase transformer, load imbalance, and neutral current
\end{abstract}

Intisari-Transformator merupakan salah satu perangkat listrik yang berperan penting dalam pendistribusian energi listrik ke pelanggan. Dalam pendistribusian energi listrik ke pelanggan, terkadang tidak semua energi yang dibangkitkan sampai ke pelanggan karena adanya rugi-rugi yang terjadi pada transformator. Pada penelitian ini penulis melakukan analisa yang terfokus di transformator distribusi 3 fasa pada penyulang 1 yang terdapat di PT. PLN (Persero) ULK Tarakan untuk mengetahui pengaruh ketidakseimbangan beban transfomator distribusi 3 fasa terhadap arus, rugirugi daya dan efisiensi transformator. Dari hasil perhitungan analisa data bahwa dari ke-38 transformator yang dapat dikatakan seimbang yang masih memenuhi syarat standar IEEE ada 19 transformator untuk pagi harinya dan 12 transformator untuk malam harinya. Sedangkan yang dapat dikatakan tidak seimbang yang sudah tidak memenuhi standar IEEE ada 19 transformator untuk pagi harinya dan ada 26 transformator untuk malam harinya. Efisiensi akan semakin besar apabila daya masuk dan daya keluar tidak mempunyai selisih yang besar atau efisiensi akan besar apabila rugi-rugi (losses) daya semakin kecil namun sebaliknya. Rugi-rugi (losses) daya akibat arus netral yang mengalir pada penghantar netral dapat dikurangi bila luas penampang di perbesar, namun diperlukan biaya yang besar

Kata Kunci-Transformator 3 fasa, ketidakseimbangan beban, dan arus netral

\section{PENDAHULUAN}

Seiring pesatnya pembangunan di Kota Tarakan diberbagai bidang maka dari itu dituntut adanya sarana dan prasarana yang dapat mendukung, yaitu sumber tenaga listrik. Saat ini tenaga listrik merupakan kebutuhan yang sangat penting, baik untuk kehidupan sehari-hari maupun kebutuhan industri. Karena sumber tenaga listrik mudah untuk disalurkan dan dikonversikan kedalam bentuk tenaga lainnya[1]. Penyediaan tenaga listrik yang baik dan stabil merupakan syarat mutlak yang harus dipenuhi dalam memenuhi kebutuhan tenaga listrik[2].

Transformator merupakan salah satu perangkat listrik yang berperan penting dalam pendistribusian energi listrik ke pelanggan[3]. Dalam pendistribusian energi listrik ke pelanggan, terkadang tidak semua energi yang dibangkitkan sampai ke pelanggan karena adanya rugirugi yang terjadi pada transformator[4]. Pada dasarnya dilakukan pembagian beban yang secara merata, karena adanya ketidaksamaan waktu penggunaan beban dan kapasitas beban akan menimbulkan ketidakseimbangan beban yang berdampak pada persediaan tenaga listrik pada transformator distribusi.

Ketidakseimbangan beban yang dimaksudkan adalah ketidakseimbangan beban antar fasa (fasa $\mathrm{R}$, fasa $\mathrm{S}$ dan fasa $\mathrm{T}$ ) menyebabkan arus mengalir dipenghantar netral transformator. Arus yang mengalir di penghantar netral transformator distribusi ini dikatakan sebagai rugi-rugi (losses) daya.

\section{LANDASAN TEORI}

\section{A. Transformator Distribusi}

Transformator distribusi adalah suatu peralatan listrik utama yang berperan penting untuk penyaluran daya listrik dalam suatu sistem distribusi, yang berfungsi untuk menurunkan tegangan distribusi primer yang merupakan tegangan menengah menjadi tegangan rendah pada sisi sekunder[5]. Transformator distribusi yang umum digunakan adalah transformator step down 20/0.4 kV, tegangan fasa-fasa sistem JTR adalah $380 \mathrm{~V}$, karena terjadi drop voltage maka tegangan rak TR dibuat diatas $380 \mathrm{~V}$ agar tegangan pada ujung beban menjadi $380 \mathrm{~V}$. Pada kumparan primer akan mengalir arus jika kumparan primer di hubungkan ke sumber listrik bolak-balik, sehingga pada inti transformator yang terbuat dari bahan feromagnet akan terbentuk sejumlah garis-garis gaya magnet (fluks)[6]. Karena arus yang mengalir merupakan arus bolak-balik maka garis-garis gaya magnet (fluks) terbentuk pada inti yang akan mempunyai arah dan jumlah yang berubah-ubah[7]. Jika arus yang mengalir berbentuk sinusoidal maka garis-garis gaya magnet (fluks) yang terjadi akan berbentuk sinusoidal pula. 
Karena garis-garis gaya magnet (fluks) tersebut yang mana pada intinya terdapat lilitan primer dan lilitan sekunder maka pada inti primer dan sekunder tersebut akan timbul GGL (Gaya Gerak Listrik) induksi, tetapi arah dari GGL induksi primer berlawanan dengan arah GGL induksi sekunder sedangkan frekuensi masingmasing tegangan tersebut sama dengan frekuensi sumbernya.

\section{B. Standar Nilai Ketidakseimbangan (IEEE std.446- 1980)}

Nilai ketidakseimbangan arus bisa dinyatakan dalam bentuk persentase (\%) sesuai dengan standar IEEE (Institute of Electrical and Electronic Engineer) Std. 4461980 (IEEE Recommended Pratice For Emergency Standby Power System For Industrial and Commercial Application) yaitu sebesar 5\% sampai 20\%. Adapun standar dan batas toleransi terlihat pada Tabel. 1

Tabel 1. Standar atau batas toleransi ketidakseimbangan beban

\begin{tabular}{|c|c|c|}
\hline No. & Parameter & Maksimum \\
\hline 1 & $\begin{array}{l}\text { Regulasi tegangan } \\
\text { keadaan mantap }\end{array}$ & $\begin{array}{c}+5,-10 \mathrm{~s} / \mathrm{d}+10 \%,-15 \% \\
(\text { ANSI C84,1-1970) } \\
\text { adalah }+6,-13 \%\end{array}$ \\
\hline 2 & $\begin{array}{c}\text { Gangguan Tegangan } \\
\text { Drop tegangan } \\
\text { sementara tegangan } \\
\text { lebih transient }\end{array}$ & $\begin{array}{c}-25 \% \text { s/d }-30 \% \text { Tidak } \\
\text { lebih dari } 0,5 \mathrm{~s} \\
-100 \% \text { dengan lama } 4 \\
\text { s/d } 20 \mathrm{~ms} \\
+150 \% \mathrm{~s} / \mathrm{d} 200 \% \text { tidak } \\
\text { boleh dari } 0,2 \mathrm{~ms}\end{array}$ \\
\hline 3 & $\begin{array}{c}\text { Distorsi tegangan } \\
\text { Harmonik }\end{array}$ & $3 \%-5 \%$ (beban linier) \\
\hline 4 & Noise & Tidak ada standar \\
\hline 5 & Variasi frekuensi & $\begin{array}{c}50 \mathrm{~Hz} \pm 0,5 \mathrm{~Hz} \text { sampai } \\
1 \mathrm{~Hz}\end{array}$ \\
\hline 6 & Perubahan frekuensi & Sekitar $1 \mathrm{~Hz}$ \\
\hline 7 & $\begin{array}{c}\text { Ketidakseimbangan } \\
\text { beban }\end{array}$ & $\begin{array}{c}5 \% \text { s/d } 20 \% \text { mak. Pada } \\
\text { setiap fasa }\end{array}$ \\
\hline 8 & $\begin{array}{c}\text { Ketidakseimbangan } \\
\text { tegangan } 3\end{array}$ & $2,5 \%$ s/d $5 \%$ \\
\hline 9 & Faktor daya & $0,18 \mathrm{~s} / \mathrm{d} 0,9$ \\
\hline 10 & Kapasitas beban & $\begin{array}{c}0,75 \mathrm{~s} / \mathrm{d} 0,85 \text { (beban } \\
\text { terpasang) }\end{array}$ \\
\hline
\end{tabular}

Keterangan:

1,2,5,6 Tegangan pada sumber daya

3,4,7 Dihasilkan dari interaksi antara sumber dan beban $8,9,10$ Tergantung pada jumlah beban

\section{METODE PENELITIAN}

\section{A. Diagram Alur Penelitian}

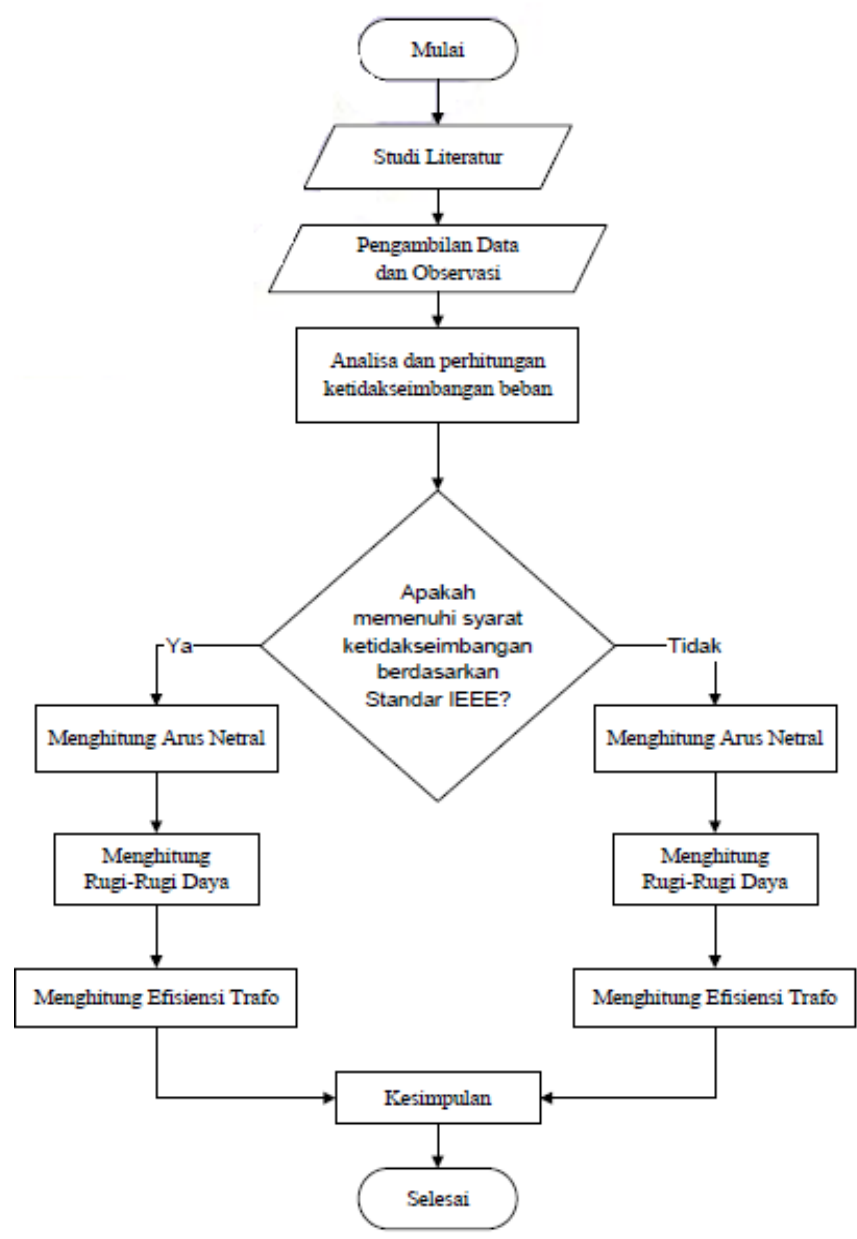

Gambar 1. Diagram Alur Proses Penelitian

\section{HASIL DAN PEMBAHASAN}

\section{A. Sistem Tenaga Listrik PT. PLN (Persero) ULK Tarakan \\ PT. PLN (Persero) ULK Tarakan memiliki 10} Penyulangyang terhubung dari pembangkit ke beban, dari 10 Penyulangdalam penelitian ini hanya akan membahas tentang beban transformator distribusi yang terdapat pada Penyulang1 PT. PLN (Persero) ULK Tarakan. Penelitian ini dilakukan dengan cara mengambil data dan observasi dilapangan, setelah itu dilanjutkan dengan menganalisis pembeban yang terjadi di Penyulang 1. Apakah pembebanan yang terjadi pada pagi hari sama dengan pembebanan yang terjadi pada malam hari.

\section{B. Data Spesifikasi Transformator Distribusi PT. PLN (Persero) ULK Tarakan}

Data spesifikasi transformator distribusi ini di ambil dari PT. PLN (Persero) ULK Tarakan. Beberapa merek transformator distibusi 3 fasa yang terdapat di Penyulang 1 di setiap gardu memiliki daya yang berbeda-beda serta pertumbuhan beban di daerah ini pun sangat pesat sehingga gardu distribusi yang terdapat di Penyulang 1 semuanya berjumlah 38 gardu yang memiliki kapasitas mulai dari 25, 50, 100, 160 sampai 200 kVA. Semakin meningkatnya pertumbuhan beban maka semakin tinggi juga kapasitas daya yang dibutuhkan pada gardu distribusi. Data spesifikasi transformator yang berada di 
Penyulang 1 PT. PLN (Persero) ULK Tarakan dapat dilihat pada Tabel 2.

Tabel 2. Prakiraan Konsumsi Energi Listrik Kabupaten Berau

\begin{tabular}{|c|c|c|c|c|}
\hline No. & $\begin{array}{l}\text { No. } \\
\text { Gardu }\end{array}$ & $\begin{array}{c}\text { Daya } \\
\text { (KVA) }\end{array}$ & Jurusan & $\begin{array}{c}\text { Tegangan } \\
\text { Primer }(\mathrm{KV})\end{array}$ \\
\hline 1 & SDM 17 & $1603 \mathrm{P}$ & 2 & 20 \\
\hline 2 & SDM 19 & $2003 \mathrm{P}$ & 1 & 20 \\
\hline 3 & SDM 20 & $2003 \mathrm{P}$ & 3 & 20 \\
\hline 4 & KBG 21 & $2003 P$ & 2 & 20 \\
\hline 5 & SDM 22 & $2003 \mathrm{P}$ & 2 & 20 \\
\hline 6 & KRA 23 & $2003 P$ & 3 & 20 \\
\hline$\overline{77}$ & SDM 24 & $2003 \mathrm{P}$ & $\overline{3}$ & 20 \\
\hline 8 & KBG 28 & $2003 \mathrm{P}$ & 3 & 20 \\
\hline 9 & KRA 29 & $2003 P$ & 3 & 20 \\
\hline 10 & KRA 39 & $1603 \mathrm{P}$ & 2 & 20 \\
\hline 11 & PAM 47 & $2003 \mathrm{P}$ & 1 & 20 \\
\hline 12 & SDM 49 & $2003 \mathrm{P}$ & 2 & 20 \\
\hline 13 & PNP 54 & $2003 \mathrm{P}$ & 3 & 20 \\
\hline 14 & KPB 65 & $2003 \mathrm{P}$ & 2 & 20 \\
\hline 15 & KBG 101 & $1003 \mathrm{P}$ & 1 & 20 \\
\hline 16 & KRA 127 & $2003 \mathrm{P}$ & 3 & 20 \\
\hline 17 & THM 134 & $2003 \mathrm{P}$ & 2 & 20 \\
\hline 18 & KBG 144 & $2003 \mathrm{P}$ & 2 & 20 \\
\hline 19 & KBG 159 & $1003 \mathrm{P}$ & 1 & 20 \\
\hline 20 & KBG 160 & $503 \mathrm{P}$ & 1 & 20 \\
\hline 21 & KBG 168 & $1603 \mathrm{P}$ & 2 & 20 \\
\hline 22 & SDM 183 & $2003 \mathrm{P}$ & 1 & 20 \\
\hline 23 & KRA 197 & $1603 \mathrm{P}$ & 2 & 20 \\
\hline 24 & KRA 201 & $2003 \mathrm{P}$ & 2 & 20 \\
\hline 25 & KBG 220 & $2003 \mathrm{P}$ & 2 & 20 \\
\hline 26 & SDM 221 & $1003 \mathrm{P}$ & 1 & 20 \\
\hline 27 & SDM 222 & $1603 \mathrm{P}$ & 2 & 20 \\
\hline 28 & KBG 238 & $2003 \mathrm{P}$ & 3 & 20 \\
\hline 29 & KPB 245 & $1603 \mathrm{P}$ & 2 & 20 \\
\hline 30 & GDS 252 & $2003 \mathrm{P}$ & 1 & 20 \\
\hline 31 & GNB 256 & $1603 \mathrm{P}$ & 1 & 20 \\
\hline 32 & SDM 286 & $1003 \mathrm{P}$ & 1 & 20 \\
\hline 33 & KRA 292 & $1003 \mathrm{P}$ & 2 & 20 \\
\hline 34 & KRA 299 & $253 \mathrm{P}$ & 1 & 20 \\
\hline 35 & KBG 311 & $1603 \mathrm{P}$ & 2 & 20 \\
\hline 36 & KRA 312 & $1603 \mathrm{P}$ & 2 & 20 \\
\hline 37 & KBG 330 & $1003 \mathrm{P}$ & 1 & 20 \\
\hline 38 & KBG 336 & $1003 \mathrm{P}$ & 1 & 20 \\
\hline
\end{tabular}

Tabel 3. Data Spesifikasi transformator distribusi pada penyulang 1

\begin{tabular}{|c|c|c|c|c|}
\hline $\begin{array}{c}\text { Tegangan } \\
\text { Sehunder } \\
\text { (V) }\end{array}$ & $\begin{array}{c}\text { Arus } \\
\text { Primer }\end{array}$ & $\begin{array}{c}\text { Arus } \\
\text { Selunder }\end{array}$ & Cos $\varphi$ & Sin $\varphi$ \\
\hline \hline 400 & 4,62 & 231 & 0,85 & 0,53 \\
\hline 400 & 5,77 & 288,67 & 0,85 & 0,53 \\
\hline 400 & 5,77 & 288,67 & 0,85 & 0,53 \\
\hline 400 & 5,77 & 288,67 & 0,85 & 0,53 \\
\hline 400 & 4,62 & 231 & 0,85 & 0,53 \\
\hline 400 & 5,77 & 288,67 & 0,85 & 0,53 \\
\hline 400 & 5,77 & 288,67 & 0,85 & 0,53 \\
\hline 400 & 5,77 & 288,67 & 0,85 & 0,53 \\
\hline 400 & 5,77 & 288,67 & 0,85 & 0,53 \\
\hline 400 & 4,62 & 231 & 0,85 & 0,53 \\
\hline 400 & 5,77 & 288,67 & 0,85 & 0,53 \\
\hline 400 & 5,77 & 288,67 & 0,85 & 0,53 \\
\hline 400 & 5,77 & 288,67 & 0,85 & 0,53 \\
\hline 400 & 5,77 & 288,67 & 0,85 & 0,53 \\
\hline 400 & 2,88 & 144,35 & 0,85 & 0,53 \\
\hline
\end{tabular}

\begin{tabular}{|c|c|c|c|c|}
\hline 400 & 1,44 & 72 & 0,85 & 0,53 \\
\hline 400 & 4,62 & 231 & 0,85 & 0,53 \\
\hline 400 & 5,77 & 288,67 & 0,85 & 0,53 \\
\hline 400 & 4,62 & 231 & 0,85 & 0,53 \\
\hline 400 & 5,77 & 288,67 & 0,85 & 0,53 \\
\hline 400 & 5,77 & 288,67 & 0,85 & 0,53 \\
\hline 400 & 2,89 & 144,35 & 0,85 & 0,53 \\
\hline 400 & 4,64 & 231 & 0,85 & 0,53 \\
\hline 400 & 5,77 & 288,67 & 0,85 & 0,53 \\
\hline 400 & 4,62 & 231 & 0,85 & 0,53 \\
\hline 400 & 5,77 & 288,68 & 0,85 & 0,53 \\
\hline 400 & 4,62 & 231 & 0,85 & 0,53 \\
\hline 400 & 2,88 & 144,35 & 0,85 & 0,53 \\
\hline 400 & 2,88 & 144,35 & 0,85 & 0,53 \\
\hline 400 & 0,72 & 36 & 0,85 & 0,53 \\
\hline 400 & 4,62 & 231 & 0,85 & 0,53 \\
\hline 400 & 4,62 & 231 & 0,85 & 0,53 \\
\hline 400 & 2,88 & 144,35 & 0,85 & 0,53 \\
\hline 400 & 2,88 & 144,35 & 0,85 & 0,53 \\
\hline
\end{tabular}

\section{Data Pengukuran Transformator Distribusi}

Data pengukuran transformator distribusi yang di peroleh dari PT. PLN (Persero) ULK Tarakan pada Penyulang 1 terdapat data pengukuran pagi dan data pengukuran malam, data pengukuran dapat dilihat pada tabel berikut ini.

Tabel 4. Data pengukuran transformator pada pagi hari

\begin{tabular}{|c|c|c|c|c|c|c|c|}
\hline \multirow{3}{*}{$\begin{array}{l}\text { No. } \\
\text { GARDU }\end{array}$} & \multirow{3}{*}{$\begin{array}{c}\mathrm{S} \\
\mathrm{kVA}\end{array}$} & \multicolumn{2}{|c|}{$\underset{\mathbf{N}}{\text { TEGANGA }}$} & \multirow{3}{*}{$\frac{\text { IN }}{A}$} & \multicolumn{3}{|c|}{ TOTAL BEBAN } \\
\hline & & L-L & L-N & & $\mathrm{R}$ & $\mathbf{s}$ & $\mathbf{T}$ \\
\hline & & $\mathbf{v}$ & $\mathbf{v}$ & & $A$ & $A$ & A \\
\hline 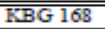 & 160 & 379 & 2220 & 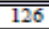 & 169 & 155 & $\overline{441}$ \\
\hline KRA 127 & 200 & 386 & 222 & 169 & 136 & 191 & 53 \\
\hline KBG 220 & 200 & 385 & 223 & 133 & 170 & 148 & 34 \\
\hline KRA 292 & 100 & 386 & 223 & 88 & 94 & 72 & 25 \\
\hline KRA 29 & 200 & 390 & 224 & 188 & 157 & 187 & 41 \\
\hline KRA 39 & 160 & 385 & 223 & 102 & 70 & 90 & 29 \\
\hline KBG 159 & 100 & 386 & 223 & 53 & 57 & 44 & 15 \\
\hline KBG 101 & 100 & 379 & 222 & 82 & 84 & 58 & 32 \\
\hline KRA 23 & 200 & 383 & 221 & 150 & 123 & 108 & 39 \\
\hline PAM 47 & 200 & 383 & 226 & 237 & 245 & 236 & 10 \\
\hline THM 134 & 200 & 387 & 221 & 215 & 164 & 209 & 52 \\
\hline KRA 197 & 160 & 381 & 223 & 133 & 112 & 145 & 30 \\
\hline KBG 21 & 200 & 382 & 224 & 170 & 160 & 130 & 42 \\
\hline KBG 336 & 100 & 382 & 226 & 113 & 58 & 62 & 56 \\
\hline KRA 312 & 160 & 387 & 223 & 98 & 114 & 49 & 64 \\
\hline GNB 256 & 160 & 384 & 225 & 80 & 97 & 123 & 40 \\
\hline SDM 183 & 200 & 387 & 222 & 36 & 28 & 32 & 10 \\
\hline KBG 160 & 50 & 383 & 222 & 44 & 37 & 49 & 13 \\
\hline GDS 252 & 200 & 386 & 224 & 190 & 198 & 207 & 15 \\
\hline KRA 299 & 25 & 385 & 226 & 20 & 36 & 29 & 17 \\
\hline KBG 144 & 200 & 391 & 226 & 131 & 170 & 122 & 50 \\
\hline KBG 238 & 200 & 389 & 222 & 217 & 172 & 185 & 49 \\
\hline KRA 201 & 200 & 392 & 225 & 158 & 154 & 145 & 16 \\
\hline PNP 54 & 200 & 383 & 221 & 115 & 117 & 107 & 16 \\
\hline KBG 311 & 160 & 382 & 221 & 106 & 129 & 133 & 32 \\
\hline KBG 330 & 100 & 386 & 222 & 14 & 27 & 6 & 26 \\
\hline KPB 245 & 160 & 385 & 222 & 83 & 84 & 80 & 5 \\
\hline KPB 65 & 200 & 385 & 222 & 103 & 107 & 81 & 35 \\
\hline SDM 19 & 200 & 393 & 224 & 94 & 87 & 127 & 38 \\
\hline SDM 20 & 200 & 382 & 221 & 128 & 92 & 176 & 75 \\
\hline SDM 221 & 100 & 386 & 223 & 8 & 32 & 37 & 30 \\
\hline SDM 49 & 200 & 383 & 221 & 98 & 102 & 75 & 25 \\
\hline SDM 22 & 160 & 383 & 221 & 103 & 130 & 131 & 35 \\
\hline SDM 24 & 200 & 385 & 223 & 158 & 137 & 172 & 37 \\
\hline SDM 222 & 160 & 386 & 223 & 64 & 111 & 57 & 56 \\
\hline SDM 17 & 160 & 384 & 222 & 204 & 199 & 179 & 25 \\
\hline SDM 286 & 100 & 383 & 222 & 153 & 122 & 134 & 32 \\
\hline KBG 28 & 200 & 390 & 227 & 87 & 98 & 82 & 17 \\
\hline
\end{tabular}

Tabel 5. Data Pengukuran Transformator pada malam hari 


\begin{tabular}{|c|c|c|c|c|c|c|c|}
\hline \multirow{3}{*}{$\begin{array}{c}\text { No. } \\
\text { GARDU }\end{array}$} & \multirow{3}{*}{$\begin{array}{c}\mathrm{S} \\
\mathrm{kVA}\end{array}$} & \multicolumn{2}{|c|}{$\underset{\mathbf{N}}{\text { TEGANGA }}$} & \multirow{3}{*}{$\frac{\text { IN }}{A}$} & \multicolumn{3}{|c|}{ TOTAL BEBAN } \\
\hline & & L-L & L-N & & $\mathrm{R}$ & $\mathrm{S}$ & $\mathrm{T}$ \\
\hline & & $\mathbf{v}$ & $\mathrm{v}$ & & A & A & A \\
\hline KBG 21 & 200 & 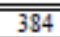 & 2225 & 209 & 170 & 1770 & $\overline{40}$ \\
\hline KRA 23 & 200 & 385 & 228 & 188 & 177 & 112 & 80 \\
\hline PAM 47 & 200 & 391 & 229 & 203 & 210 & 212 & 13 \\
\hline KRA 29 & 200 & 388 & 226 & 156 & 186 & 228 & 67 \\
\hline KBG 101 & 100 & 386 & 225 & 136 & 125 & 137 & 15 \\
\hline KRA 39 & 160 & 381 & 222 & 125 & 92 & 80 & 50 \\
\hline KRA 127 & 200 & 381 & 222 & 171 & 194 & 104 & 89 \\
\hline KBG 160 & 50 & 381 & 222 & 49 & 44 & 69 & 23 \\
\hline KRA 201 & 200 & 382 & 222 & 271 & 218 & 220 & 57 \\
\hline KBG 168 & 160 & 382 & 222 & 130 & 194 & 209 & 80 \\
\hline THM 134 & 200 & 385 & 224 & 225 & 178 & 230 & 56 \\
\hline KBG 159 & 100 & 388 & 227 & 76 & 92 & 69 & 22 \\
\hline KRA 197 & 160 & 381 & 221 & 263 & 209 & 269 & 61 \\
\hline GDS 252 & 200 & 385 & 221 & 120 & 122 & 130 & 14 \\
\hline KBG 311 & 160 & 386 & 223 & 141 & 169 & 194 & 49 \\
\hline KRA 312 & 160 & 382 & 222 & 119 & 126 & 64 & 65 \\
\hline KBG 330 & 100 & 385 & 224 & 22 & 29 & 10 & 15 \\
\hline KBG 336 & 100 & 385 & 223 & 121 & 53 & 70 & 56 \\
\hline SDM 49 & 200 & 383 & 222 & 98 & 76 & 77 & 28 \\
\hline PNP 54 & 200 & 384 & 223 & 180 & 190 & 179 & 12 \\
\hline KBG 144 & 200 & 382 & 223 & 229 & 183 & 154 & 62 \\
\hline SDM 183 & 200 & 385 & 223 & 50 & 30 & 40 & 20 \\
\hline KBG 238 & 200 & 386 & 225 & 234 & 232 & 248 & 20 \\
\hline SDM 221 & 100 & 383 & 224 & 11 & 20 & 25 & 11 \\
\hline GNB 256 & 160 & 381 & 223 & 20 & 22 & 15 & 9 \\
\hline SDM 286 & 100 & 379 & 221 & 61 & 77 & 105 & 40 \\
\hline KRA 292 & 100 & 385 & 223 & 107 & 98 & 91 & 19 \\
\hline KRA 299 & 25 & 382 & 221 & 17 & 30 & 25 & 13 \\
\hline SDM 17 & 160 & 382 & 221 & 194 & 183 & 162 & 30 \\
\hline KPB 245 & 160 & 386 & 224 & 156 & 154 & 107 & 60 \\
\hline KPB 65 & 200 & 380 & 223 & 171 & 194 & 104 & 76 \\
\hline SDM 19 & 200 & 395 & 224 & 198 & 102 & 168 & 86 \\
\hline SDM 20 & 200 & 381 & 221 & 201 & 165 & 199 & 34 \\
\hline SDM 22 & 160 & 383 & 222 & 122 & 113 & 167 & 55 \\
\hline KBG 220 & 200 & 386 & 222 & 133 & 139 & 157 & 25 \\
\hline KBG 28 & 200 & 383 & 221 & 146 & 179 & 178 & 30 \\
\hline $\operatorname{SDM} 222$ & 160 & 385 & 227 & 106 & 135 & 85 & 44 \\
\hline SDM 24 & 200 & 38. & 22. & 165 & 11 & 80 & 68 \\
\hline
\end{tabular}

\section{Data Perhitungan Transformator Distribusi}

Dari data pengukuran kita dapat menghitung analisis beban puncak, segitiga daya, analisis ketidakseimbangan beban, analisis akibat dari ketidakseimbangan beban, analisis rugi-rugi (losses) daya dan efisiensi transformator distribusi pada gardu SDM 17 yang terdapat pada Penyulang 1.

\section{E. Analisis Beban Puncak Transformator}

Dalam analisis beban ini perlu diketahui terlebih dahulu arus beban penuh denganmenggunakan persamaan berikut dan nilai dari Tabel (3) adalah:

$$
I_{F L}=\frac{S}{V_{L-L}}=\frac{160.000}{400}=400 \mathrm{~A}
$$

dengan:

$\mathrm{IF}=$ Arus beban penuh pada beban 3 fasa $(\mathrm{A})$

$\mathrm{S}=$ Daya pada transformator $(\mathrm{VA})$

$\mathrm{V}_{\mathrm{L}}=$ Tegangan pada sisi sekunder transformator pada tabel spesifikasi (V)

Untuk mencari arus rata-rata dengan persamaan (2.3) adalah:

1. Pada pagi hari (nilai dari tabel 4)

$$
\begin{aligned}
& I_{\text {rata }- \text { rata }}=\frac{\left.\left(I_{R} \times \sqrt{3}\right)+\left(I_{S} \times \sqrt{3}\right)+I_{T} \times \sqrt{3}\right)}{3} \\
& =\frac{(204 \times \sqrt{3})+(199 \times \sqrt{3})^{+}+(179 \times \sqrt{3})}{3} \\
& =336,02 \mathrm{~A}
\end{aligned}
$$

2. Pada Malam hari (nilai dari tabel 5)

$$
\begin{aligned}
& I_{\text {ratu }- \text { rata }}=\frac{\left.\left(I_{R} \times \sqrt{3}\right)+\left(I_{S} \times \sqrt{3}\right)+I_{T} \times \sqrt{3}\right)}{3} \\
& =\frac{(194 \times \sqrt{3})+(183 \times \sqrt{3})+(162 \times \sqrt{3})}{3} \\
& =311,19 \mathrm{~A}
\end{aligned}
$$

Jadi persentase pembebanan dapat dihitung dengan persamaan adalah:

a. Pagi hari :

$$
\frac{I_{\text {ruta }- \text { rata }}}{I_{F L}} \times 100 \%=\frac{336,02}{400} \times 100 \%=84 \%
$$

b. Malam hari :

$$
\begin{aligned}
\frac{I_{\text {ruta }- \text { rutu }}}{I_{F L}} \times 100 \%= & \frac{311,19}{400} \times 100 \% \\
& =77,80 \%
\end{aligned}
$$

Dari hasil yang diperoleh menunjukkan bahwa beban puncak terjadi pada pagi hari yaitu $84 \%$.

\section{F. Analisis Segitiga Daya pada Transformator}

Untuk mencari daya semu dengan persamaan sebagai berikut.

1. Pada pagi hari nilai dari tabel 4 .

$$
\begin{aligned}
S=V_{L-L} \times \text { Irata-rata } & =384 \times 336,02 \\
& =129.031,68 \mathrm{VA}
\end{aligned}
$$$$
=129,03 \mathrm{kVA}
$$

2. Pada malam hari nilai dari tabel 5 .

$$
\begin{aligned}
S=V_{L-L \times I} \text { rata-rata } & =382 \times 311,19 \\
& =118.874,58 \mathrm{VA} \\
& =118,88 \mathrm{kVA}
\end{aligned}
$$

$\mathrm{S}=$ Daya semu 3 fasa (VA)

$\mathrm{V}_{\mathrm{L}-\mathrm{L}}=$ Tegangan 3 fasa $(\mathrm{V})$

Irata-rata $=$ Arus rata-rata 3 fasa $(\mathrm{A})$

Untuk Mencari daya aktif dengan persamaan sebagai berikut :

1. Pada pagi hari nilai dari tabel 3 dan 4

$$
\begin{aligned}
P=V_{L-L} \times I_{\text {rata }- \text { rata }} & \times \cos \varphi \\
& =384 \times 336,02 \\
& \times 0,85 \\
& =109.676,92 \mathrm{~W} \\
& =109,68 \mathrm{~kW}
\end{aligned}
$$

2. Pada malam hari dari tabel 3 dan 5

$$
\begin{aligned}
P=V_{L-L} \times I_{\text {rata }- \text { rata }} & \times \cos \varphi \\
& =382 \times 311,19 \\
& \times 0,85 \\
& =101.043,39 \mathrm{~W} \\
& =101,04 \mathrm{~kW}
\end{aligned}
$$

\section{G. Analisis Ketidakseimbangan Beban}

Dengan persamaan berikut, koefisien $a, b$ dan $c$ dapat diketahui besarnya, dimana besarnya arus perfasa dalam keadaan seimbang ( $3 \times I)$ sama dengan besarnya arus rata-rata (Irata-rata) dengan persamaan-persamaan berikut:

1. Pada pagi hari nilai dari tabel 4 . 


$$
\begin{aligned}
& a=\frac{\sqrt{3} \times I_{R}}{I_{\text {rata }}-\text { rata }}=\frac{\sqrt{3} \times 204}{336,02}=1,05 \\
& b=\frac{\sqrt{3} \times I_{S}}{I_{\text {rata }}-\text { rata }}=\frac{\sqrt{3} \times 199}{336,02}=1,03 \\
& c=\frac{\sqrt{3} \times I_{T}}{I_{\text {rata }- \text { rata }}}=\frac{\sqrt{3} \times 179}{336,02}=0,92
\end{aligned}
$$

Jadi persentase ketidakseimbangan beban dalam(\%) adalah :

$$
\begin{aligned}
& =\frac{\{|a-1|\}+\{|b-1|\}+\{|c-1|\}}{3} \times 100 \% \\
& =\frac{\{|1,05-1|\}+\{|1,03-1|\}+\{|0,92-1|\}}{3} \times 100 \% \\
& =5,15 \%
\end{aligned}
$$

2. Pada malam hari nilai diambil dari tabel 5.

$$
\begin{aligned}
& a=\frac{\sqrt{3} I_{R}}{I_{\text {rata-rata }}}=\frac{\sqrt{3} \times 194}{311,19}=1,08 \\
& b=\frac{\sqrt{3} I_{S}}{I_{\text {rata-rata }}}=\frac{\sqrt{3} \times 183}{311,19}=1,02 \\
& c=\frac{\sqrt{3} I_{T}}{I_{\text {rata }} \text {-rata }}=\frac{\sqrt{3} \times 162}{311,19}=0,90
\end{aligned}
$$

Jadi persentase ketidakseimbangan beban dalam (\%) adalah :

$$
\begin{aligned}
& =\frac{\{|a-1|\}+\{|b-1|\}+\{|c-1|\}}{3} \times 100 \% \\
& =\frac{\{|1,08-1|\}+\{|1,02-1|\}+\{|0,90-1|\}}{3} \times 100 \% \\
& =6,56 \%
\end{aligned}
$$

\section{H. Analisis Efisiensi Transformator}

Untuk mengetahui nilai efisiensi adalah dengan menggunakan persamaan sebaai berikut :

$$
\eta=\frac{P_{\text {out }}}{P_{\text {in }}} \times 100 \%
$$

1. Pada Pagi hari tabel 3 dan 4

$$
\begin{aligned}
P_{\text {out }} & =(a+b+c) V_{L-N} \times I_{L-N} \times \cos \varphi \\
& =(1,05+1,03+0,92) 222 \times 194 \times 0,85 \\
& =109.823,4 \mathrm{~W} \\
& =109,82 \mathrm{~kW}
\end{aligned}
$$

Jadi efisiensi transformator pada pagi hari adalah :

$$
\begin{aligned}
\eta= & \frac{P_{\text {out }}}{P_{\text {in }}} \times 100 \% \\
& =\frac{P_{\text {out }}}{P_{\text {out }}+P_{\text {losse }}} \times 100 \% \\
& =\frac{109,82}{109,82+0,0044} \times 100 \% \\
& =100 \%
\end{aligned}
$$

\begin{tabular}{|c|c|c|c|c|}
\hline No & $\begin{array}{c}\text { No. } \\
\text { GARDU }\end{array}$ & $\begin{array}{c}\text { IRATA } \\
\text {-RATA } \\
\text { (A) }\end{array}$ & $\begin{array}{c}\text { PERENTA } \\
\text { SE } \\
\text { PEMBEBA } \\
\text { NAN } \\
(96) \\
\end{array}$ & $\begin{array}{c}\text { RATA-RATA } \\
\text { KETIDAKSEI } \\
\text { MBANGAN } \\
\text { BEBAN } \\
(\%) \\
\end{array}$ \\
\hline 1 & $\mathrm{KBG} 168$ & 259.81 & 64,95 & 10,67 \\
\hline 2 & KRA 127 & 286,37 & 57,27 & 11,83 \\
\hline 3 & KBG 220 & 260,38 & 52,08 & 8,72 \\
\hline 4 & KRA 292 & 146,65 & 58,66 & 9,97 \\
\hline 5 & KRA 29 & 307,15 & 61,43 & 7,64 \\
\hline 6 & KRA 39 & 151,27 & 37,82 & 13,23 \\
\hline 7 & KBG 159 & 88,91 & 35,56 & 9,52 \\
\hline 8 & KBG 101 & 129,33 & 51,73 & 14,88 \\
\hline 9 & KRA 23 & 219,97 & 43,99 & 12,07 \\
\hline 10 & PAM 47 & 414,54 & 82,91 & 1,58 \\
\hline 11 & THM 134 & 339,48 & 67,9 & 10,88 \\
\hline 12 & KRA 197 & 225,74 & 56,44 & 9,38 \\
\hline 13 & KBG 21 & 265,58 & 53,12 & 10,14 \\
\hline 14 & KBG 336 & 134,52 & 53,81 & 30,33 \\
\hline 15 & KRA 312 & 150,69 & 37,67 & 29,12 \\
\hline 16 & GNB 256 & 173,21 & 43,3 & 15,33 \\
\hline 17 & SDM 183 & 55,43 & 11,09 & 8,33 \\
\hline 18 & KBG 160 & 75,06 & 60,04 & 9,74 \\
\hline 19 & GDS 252 & 343,52 & 68,7 & 2,91 \\
\hline 20 & KRA 299 & 49,07 & 78,52 & 19,61 \\
\hline 21 & KBG 144 & 244,22 & 48,84 & 13,71 \\
\hline 22 & KBG 238 & 331,4 & 66,28 & 8,94 \\
\hline 23 & KRA 201 & 264,43 & 52,39 & 2,91 \\
\hline 24 & PNP 54 & 195,72 & 39,14 & 3,54 \\
\hline 25 & KBG 311 & 212,46 & 53,12 & 9,06 \\
\hline 26 & KBG 330 & 27,14 & 10,85 & 48,23 \\
\hline 27 & KPB 245 & 142,61 & 35,65 & 1,89 \\
\hline 28 & KPB 65 & 168,01 & 33,6 & 11 \\
\hline 29 & SDM 19 & 177,82 & 35,56 & 15,8 \\
\hline 30 & SDM 20 & 228,63 & 45,73 & 22,22 \\
\hline 31 & SDM 221 & 44,46 & 17,78 & 45,89 \\
\hline 32 & SDM 49 & 158,77 & 31,75 & 12,12 \\
\hline 33 & SDM 22 & 210,16 & 52,54 & 10,07 \\
\hline 34 & SDM 24 & 269,62 & 53,92 & 7,99 \\
\hline 35 & SDM 222 & 133,95 & 33,49 & 29,02 \\
\hline 36 & SDM 17 & 336,02 & 84 & 5,15 \\
\hline 37 & SDM 286 & 236,14 & 94,45 & 8,15 \\
\hline 38 & $\mathrm{KBG} 28$ & 154,15 & 30,83 & 6,74 \\
\hline
\end{tabular}

2. Pada malam hari tabel 3 dan 5

$$
\begin{aligned}
P_{\text {out }} & =(a+b+c) V_{L-N \times I_{L-N} \times \cos \varphi} \\
& =1,08+1,02+0,90221 \times 179,67 \times 0,85 \\
& =101.253,02 \mathrm{~W} \\
& =101,25 \mathrm{~kW}
\end{aligned}
$$

Jadi efisiensi transformator pada malam hari adalah :

$$
\begin{gathered}
\eta=\frac{P_{\text {out }}}{P_{\text {in }}} \times 100 \% \\
=\frac{101,25}{P_{\text {out }}+P_{\text {losses }}} \times 100 \% \\
=\frac{P_{\text {out }}}{101,25+0,0066} \times 100 \% \\
=99,99 \% \\
\eta=\text { Efisiensi transformator }(\%)
\end{gathered}
$$

$\mathrm{P}_{i n}=$ Daya masuk $(\mathrm{W})$

$$
\begin{aligned}
& \text { Pout }=\text { Daya keluar }(\mathrm{W}) \\
& \mathrm{P}_{\text {losses }}=\mathrm{P}_{\mathrm{N}}
\end{aligned}
$$

Dari hasil perhitungan dengan persamaan diatas kita dapat mengetahui ketidakseimbangan beban yang terjadi pada pagi hari dan malam hari. Ketidakseimbangan beban lebih besar terjadi pada pagi hari karena penggunaaan beban pada transformator SDM 17 adalah perkantoran yang dimana beban yang digunakan lebih besar di pagi hari daripada malam harinya. Untuk perhitungan selanjutnya dapat dilihat pada Tabel 6 dan 7 dengan menggunakan persamaan-persamaan diatas.

Tabel 6. Data hasil perhitungan transformator pada pagi

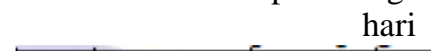

Tabel 7 data hasil perhitungan transformator pada malam hari 


\begin{tabular}{|c|c|c|c|c|}
\hline No & $\begin{array}{c}\text { No. } \\
\text { GARDU }\end{array}$ & $\begin{array}{c}\text { IRATA } \\
\text {-RATA }\end{array}$ & $\begin{array}{c}\text { PERENTA } \\
\text { SE } \\
\text { PEMBEA } \\
\text { NAN } \\
(9,6)\end{array}$ & $\begin{array}{c}\text { RATA-RATA } \\
\text { KETMAKSEI } \\
\text { MBANGAN } \\
\text { BEBAN } \\
(\%)\end{array}$ \\
\hline \hline 1 & KBG 21 & 316,97 & 63,39 & 9,47 \\
\hline 2 & KRA 23 & 275,4 & 55,08 & 19,71 \\
\hline 3 & PAM 47 & 360,84 & 72,17 & 1,71 \\
\hline 4 & KRA 29 & 329,09 & 65,82 & 13,33 \\
\hline 5 & KBG 101 & 229,79 & 91,91 & 3,85 \\
\hline 6 & KRA 39 & 171,47 & 42,87 & 17,51 \\
\hline 7 & KRA 127 & 270,78 & 54,16 & 22,32 \\
\hline 8 & KBG 160 & 93,53 & 74,82 & 18,52 \\
\hline 9 & KRA 201 & 409,34 & 81,87 & 9,78 \\
\hline 10 & KBG 168 & 307,73 & 76,93 & 17,89 \\
\hline 11 & THM 134 & 365,46 & 73,09 & 10,43 \\
\hline 12 & KBG 159 & 136,83 & 54,73 & 10,97 \\
\hline 13 & KRA 197 & 427,82 & 106,95 & 10,26 \\
\hline 14 & GDS 252 & 214,77 & 42,95 & 3,23 \\
\hline 15 & KBG 311 & 290,98 & 72,75 & 10,71 \\
\hline 16 & KRA 312 & 178,4 & 44,6 & 25,24 \\
\hline 17 & KBG 330 & 35,22 & 14,09 & 33,88 \\
\hline 18 & KBG 336 & 140,87 & 56,35 & 32,51 \\
\hline 19 & SDM 49 & 144,91 & 28,98 & 11,42 \\
\hline 20 & PNP 54 & 316,97 & 63,39 & 2,55 \\
\hline 21 & KBG 144 & 326,78 & 65,36 & 14,25 \\
\hline 22 & SDM 183 & 69,28 & 13,86 & 16,67 \\
\hline 23 & KBG 238 & 412,23 & 82,45 & 2,8 \\
\hline 24 & SDM 221 & 32,33 & 12,93 & 27,38 \\
\hline 25 & GNB 256 & 32,91 & 8,23 & 14,04 \\
\hline 26 & SDM 286 & 140,3 & 56,12 & 19,75 \\
\hline 27 & KRA 292 & 170,9 & 68,36 & 5,63 \\
\hline 28 & KRA 299 & 41,57 & 66,51 & 19,44 \\
\hline 29 & SDM 17 & 311,19 & 77,8 & 6,56 \\
\hline 30 & KPB 245 & 240,76 & 60,19 & 15,35 \\
\hline 31 & KPB 65 & 270,78 & 54,16 & 22,32 \\
\hline 32 & SDM 19 & 270,2 & 54,04 & 23,08 \\
\hline 33 & SDM 20 & 326,2 & 65,24 & 8,26 \\
\hline 34 & SDM 22 & 232,09 & 58,02 & 16,42 \\
\hline 35 & KBG 220 & 247,68 & 49,54 & 6,53 \\
\hline 36 & KBG 28 & 290,41 & 58,08 & 8,61 \\
\hline 37 & SDM 222 & 188,22 & 47,05 & 16,16 \\
\hline 38 & SDM 24 & 262,69 & 52,54 & 18,32 \\
\hline
\end{tabular}

Dari hasil perhitungan didapatlah persentase pembebanan yang ada di Penyulang 1 PT. PLN (Persero) ULK Tarakan. Nilai ketidakseimbangan bisa dinyatakan dalam bentuk persentase (\%) sesuai dengan standar IEEE Std. 4461980 (IEEE Recommended Pratice For Emergency Standby Power System For Industrial and Commercial Application) nilai toleransi 5\% sampai $20 \%$.

Ketidakseimbangan beban yang terjadi pada transformator distribusi dikarenakan beban-beban yang berada di fasa $R$, fasa $S$ dan fasa $T$ tidak seimbang (memiliki selisih yang jauh). Pada dasarnya dilakukan pembagian beban yang secara merata, karena adanya ketidaksamaan waktu penggunaan beban dan kapasitas beban maka timbullah ketidakseimbangan beban yang berdampak pada penyediaan tenaga listrik pada transformator distribusi SDM 17. Untuk mengurangi ketidakseimbangan beban yang terjadi dapat dilakukan pemerataan beban yang ada di fasa $R$, fasa $S$ dan fasa $T$. Akibat terjadinya ketidakseimbangan beban yang terjadi pada fasa $\mathrm{R}$, fasa $\mathrm{S}$ dan fasa $\mathrm{T}$ di transformator maka timbullah arus netral yang mengalir di penghantar netral. Selain itu timbulah rugi-rugi(losses) pada penghantar netral yang hasilnya dapat dilihat pada Tabel 8 dan 9 .
Tabel 8. Data hasil perhitungan rugi-rugi (losses) yang mengalir pada penghantar netral pada transformator yang masih dalam keadaan seimbang

\begin{tabular}{|c|c|c|c|c|c|c|}
\hline \multirow{2}{*}{\begin{tabular}{|l|l}
$\underline{E}$ \\
$\frac{E}{m}$ \\
$z$
\end{tabular}} & \multirow{2}{*}{$\begin{array}{c}\text { No. } \\
\text { GARDU }\end{array}$} & \multicolumn{2}{|c|}{ Arus Netral } & \multicolumn{2}{|c|}{$P_{\mathrm{N}}$} & \multirow{2}{*}{$\begin{array}{c}\begin{array}{c}\text { Efisie } \\
\text { nsi }\end{array} \\
\%\end{array}$} \\
\hline & & $A$ & $\theta$ & $\mathrm{kW}$ & $9 \%$ & \\
\hline \multirow{32}{*}{$\begin{array}{l}\bar{y} \\
\frac{a}{x} \\
\frac{5}{x} \\
\frac{x}{a}\end{array}$} & KBG 168 & 37,98 & 309,6 & 0,0119 & 0,0143 & 99,99 \\
\hline & KRA 127 & 47,95 & 64,79 & 0,019 & 0,0203 & 99,98 \\
\hline & KBG 220 & 32,23 & 291.97 & 0,0086 & 0,0101 & 99,99 \\
\hline & KRA 292 & 19,7 & 223,5 & 0,0032 & 0,0067 & 99,99 \\
\hline & KRA 29 & 30,51 & 89,83 & 0,0077 & 0,0076 & 99,99 \\
\hline & KRA 39 & 28 & 110 & 0,0065 & 0,0131 & 99,99 \\
\hline & KBG 159 & 11,53 & 225,67 & 0,0011 & 0,0038 & 100 \\
\hline & KBG 101 & 25,06 & 212,17 & 0,0052 & 0,0125 & 99,99 \\
\hline & KRA 23 & 36,86 & 168,84 & 0,0113 & 0,0157 & 99,98 \\
\hline & PAM 47 & 8,54 & 262,39 & 0,0006 & 0,0004 & 100 \\
\hline & THM 134 & 48,28 & 94,39 & 0,0193 & 0,0173 & 99,98 \\
\hline & KRA 197 & 29,72 & 65,95 & 0,0073 & 0,01 & 99,99 \\
\hline & KBG 21 & 36,06 & 194,31 & 0,0108 & 0,0125 & 99,99 \\
\hline & GNB 256 & 37,51 & 5,1 & 0,0116 & 0,0206 & 99,98 \\
\hline & SDM 183 & 6,93 & 118,21 & 0,0004 & 0,0022 & 100 \\
\hline & KBG 160 & 10,44 & 63,71 & 0,0009 & 0,0037 & 100 \\
\hline & GDS 252 & 14,73 & 0,16 & 0,0018 & 0,0016 & 100 \\
\hline & KRA 299 & 13,89 & 302,34 & 0,0016 & 0,01 & 99,99 \\
\hline & KBG 144 & 44,2 & 258,05 & 0,0162 & 0,0199 & 99,98 \\
\hline & KBG 238 & 40,11 & 311,91 & 0,0133 & 0,0122 & 99,99 \\
\hline & KRA 201 & 10,58 & 189,08 & 0,0009 & 0,0011 & 100 \\
\hline & PNP 54 & 9,16 & 219,11 & 0,0007 & 0,0011 & 100 \\
\hline & KBG 311 & 25,24 & 336,09 & 0,0053 & 0,0076 & 99,99 \\
\hline & KPB 245 & 3,6 & 222,19 & 0,0001 & 0,0002 & 100 \\
\hline & KPB 65 & 24,25 & 216,43 & 0,0049 & 0,0089 & 99,99 \\
\hline & SDM 19 & 37 & 37,64 & 0,0113 & 0,0191 & 99,98 \\
\hline & SDM 49 & 25,24 & 216,1 & 0,0053 & 0,0102 & 99,99 \\
\hline & $\operatorname{SDM} 22$ & 27,51 & 330,02 & 0,0063 & 0,0092 & 99,99 \\
\hline & SDM 24 & 30,51 & 64,8 & 0,0077 & 0,0087 & 99,99 \\
\hline & SDM 17 & 22,91 & 197,32 & 0,0043 & 0,004 & 100 \\
\hline & SDM 286 & 27,07 & 125,65 & 0,0061 & 0,0079 & 99,99 \\
\hline & KBG 28 & 14,18 & 70,43 & 0,0017 & 0,0033 & 100 \\
\hline \multirow{31}{*}{$\begin{array}{l}\frac{\vec{z}}{2} \\
\frac{3}{2} \\
\frac{3}{2} \\
\frac{2}{2}\end{array}$} & KBG 21 & 39 & 148,22 & 0,0126 & 0,0122 & 99,99 \\
\hline & KRA 23 & 71,14 & 200,51 & 0,0419 & 0,0465 & 99,95 \\
\hline & PAM 47 & 8,18 & 340,44 & 0,0005 & 0,0005 & 100 \\
\hline & KRA 29 & 62,64 & 183,71 & 0,0325 & 0,0299 & 99,97 \\
\hline & KBG 101 & 11,53 & 83,93 & 0,0011 & 0,0015 & 100 \\
\hline & KRA 39 & 40,36 & 163,13 & 0,0135 & 0,0243 & 99,98 \\
\hline & KBG 160 & 22,91 & 219,1 & 0,0043 & 0,0143 & 99,99 \\
\hline & KRA 201 & 52,03 & 146,31 & 0,0224 & 0,0169 & 99,98 \\
\hline & KBG 168 & 72,67 & 338,51 & 0,0437 & 0,0438 & 99,96 \\
\hline & THM 134 & 49,69 & 83,22 & 0,0204 & 0,0171 & 99,98 \\
\hline & KBG 159 & 20,42 & 250,94 & 0,0035 & 0,0077 & 99,99 \\
\hline & KRA 197 & 57,24 & 83,01 & 0,0271 & 0,0196 & 99,98 \\
\hline & GDS 252 & 9,17 & 197,33 & 0,0007 & 0,001 & 100 \\
\hline & KBG 311 & 45,92 & 356,34 & 0,0175 & 0,0183 & 99,98 \\
\hline & SDM 49 & 21,52 & 145,91 & 0,0038 & 0,0081 & 99,99 \\
\hline & PNP 54 & 10,54 & 263,52 & 0,0009 & 0,0009 & 100 \\
\hline & KBG 144 & 65,51 & 170,76 & 0,0355 & 0,0335 & 99,97 \\
\hline & SDM 183 & 17,32 & 118,22 & 0,0025 & 0,011 & 99.99 \\
\hline & KBG 238 & 15,1 & 214,81 & 0,0019 & 0,0014 & 100 \\
\hline & GNB 256 & 6,24 & 224,29 & 0,0003 & 0,003 & 100 \\
\hline & SDM 286 & 38,57 & 187,16 & 0,0123 & 0,0273 & 99,97 \\
\hline & KRA 292 & 13,89 & 174,09 & 0,0016 & 0,0029 & 100 \\
\hline & KRA 299 & 11,35 & 305,79 & 0,0011 & 0,0079 & 99,99 \\
\hline & SDM 17 & 28,16 & 188,43 & 0,0066 & 0,0065 & 99,99 \\
\hline & KPB 245 & 48,03 & 206,14 & 0,0191 & 0,0242 & 99,98 \\
\hline & SDM 20 & 35,04 & 91,04 & 0,0102 & 0,0096 & 99,99 \\
\hline & SDM 22 & 50,11 & 37,16 & 0,0208 & 0,0275 & 99,97 \\
\hline & KBG 220 & 21.63 & 194.32 & 0.0039 & 0.0048 & 100 \\
\hline & $\mathrm{KBG} 28$ & 32,51 & 326,68 & 0,0088 & 0,0093 & 99,99 \\
\hline & KBG 29 & 43,56 & 243,54 & 0,0157 & 0,0255 & 99,98 \\
\hline & KBG 30 & 63,84 & 256,47 & 0,0337 & 0,0396 & 99,96 \\
\hline
\end{tabular}


Tabel 9. Data hasil perhitungan rugi-rugi (losses) yang mengalir pada penghantar netral pada transformator yang sudah tidak dalam keaadan seimbang

\begin{tabular}{|c|c|c|c|c|c|c|}
\hline \multirow{2}{*}{$\frac{E}{\frac{E}{\pi}}$} & \multirow{2}{*}{$\begin{array}{c}\text { No. } \\
\text { GARDU }\end{array}$} & \multicolumn{2}{|c|}{ Arus Netral } & \multicolumn{2}{|c|}{ PN } & \multirow{2}{*}{$\begin{array}{c}\text { efesie } \\
\text { nsi } \\
96\end{array}$} \\
\hline & & A & $\theta$ & $\mathrm{kW}$ & $\%$ & \\
\hline \multirow{6}{*}{ 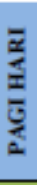 } & KBG 336 & 53,11 & 144,47 & 0,0234 & 0,0535 & 99.95 \\
\hline & KRA 312 & 58,66 & 221.87 & 0,0285 & 0,0575 & 99.94 \\
\hline & KBG 330 & 18,36 & 246,04 & 0,0028 & 0,0313 & 99,97 \\
\hline & SDM 20 & 72,99 & 53,5 & 0,0441 & 0,0594 & 99.94 \\
\hline & SDM 221 & 26,85 & 337,49 & 0,006 & 0,0409 & 99,96 \\
\hline & SDM 222 & 50,86 & 261,37 & 0,0214 & 0,0487 & 99.95 \\
\hline \multirow{7}{*}{$\begin{array}{l}\bar{x} \\
\frac{\pi}{2} \\
\bar{z} \\
\frac{3}{3} \\
\frac{1}{2}\end{array}$} & KRA 127 & 80,99 & 222,45 & 0,0543 & 0,0619 & 99,94 \\
\hline & KRA 312 & 58,81 & 214,13 & 0,0286 & 0,0494 & 99,95 \\
\hline & KBG 330 & 16,64 & 229,58 & 0,0023 & 0,0199 & 99,98 \\
\hline & KBG 336 & 61,3 & 134,31 & 0,0311 & 0,0675 & 99,93 \\
\hline & SDM 221 & 12,29 & 168,84 & 0,0013 & 0,0119 & 99,99 \\
\hline & KPB 65 & 80,99 & 222,45 & 0,0543 & 0,0621 & 99.94 \\
\hline & SDM 19 & 85,06 & 74 & 0,0599 & 0,066 & 99,93 \\
\hline
\end{tabular}

Arus netral yang mengalir di penghantar netral transformator dapat menimbulkan rugi-rugi (losses) daya. Besar kecilnya rugi-rugi (losses) dayayang terjadi dipengaruhi oleh besar kecilnya arus netral yang mengalir pada penghantar netral dan dari hasil perhitungan efisiensi juga dapat diketahui untuk memperoleh nilai efisiensi yang besar maka harus diusahakan rugi-rugi (losses) daya yang terjadi kecil.

\section{KESIMPULAN}

Dari hasil perhitungan dan analisa data dapat diambil kesimpulan seperti berikut:

A. Waktu Beban Puncak (WBP) terjadi pada pagi hari dimana persentase pembebanan adalah $84 \%$ lebih besar daripada persentase pembebanan di malam harinya adalah $77,80 \%$. Dimana penggunaan beban transformator SDM 17 adalah untuk perkantoran yang lebih banyak menggunakan energi listrik dipagi harinya dari pada malam harinya.

B. Dari ke-38 transformator yang dapat dikatakan seimbang yang masih memenuhi syarat standar IEEE ada 32 transformator untuk pagi harinya dan 31 transformator untuk malam harinya. Sedangkan yang dapat dikatakan tidak seimbang yang sudah tidak memenuhi standar IEEE ada 6 transformator untuk pagi harinya dan ada 7 transformator untuk malam harinya.

C. Besar kecilnya selisih nilai beban arus pada fasa R, fasa $\mathrm{S}$ dan fasa $\mathrm{T}$ akan mempengaruhi nilai rata-rata kesetidakseimbangan beban dan nilai arus yang mengalir dipengahantar netral transformator.

D. Rugi-rugi (losses) daya yang terjadi pada transformator akan semakin besar apabila arus yang mengalir di penghantar netral transformator semakin besar dan sebaliknya.

E. Efisiensi akan semakin besar apabila daya masuk dan daya keluar tidak mempunyai selisih yang besar atau efisiensi akan besar apabila rugi-rugi (losses) daya semakin kecil namun sebaliknya.

F. Rugi-rugi (losses) daya akibat arus netral yang mengalir pada penghantar netral dapat dikurangi bila luas penampang di perbesar, namun diperlukan biaya yang besar.

\section{REFERENSI}

[1] Cekdin, Cekmas dan Barlian, Taufik. 2013. Transmisi Daya Listrik. Yogyakarta: ANDI Yogyakarta.

[2] Handajadi, Wiwik. (2010). "Optimalisasi dan Peningkatan Efesiensi Penggunaan Energi Listrik pada Peralatan Listrik Untuk Proses Kimia". Prosiding Seminar Nasional Aplikasi SAINS dan Teknologi. Institu SAINS \& Teknologi AKPRINDO. Yogyakarta. Hal. A56-A60

[3] Hidayat, Sopiar Noor. 2017. Analisa Beban Transformator Distribusi 3 Fasa Pada Feeder 3 PT. PLN Nunukan. Skripsi. Tarakan: Univ. Borneo Tarakan.

[4] Kadir, Abdul. 2000. Distribusi dan Utilisasi Tenaga Listrik. Jakarta:Penerbit Universitas Indonesia (UIPress)

[5] Siregar, MHD. Arifin. 2013. Analisis Ketidakseimbangan Beban pada Transformator Distribusi Di PT. PLN (Persero) Rayon Panam Pekan Baru. Pekan Baru: Univ. Islam Negeri Sultan Syarif Kasim Riau.

[6] Suhadi, dkk. 2008. Teknik Distribusi Tenaga Listik Jilid 1. Jakarta: Direktorat Pembinaan Sekolah Menengah Kejuruan.

[7] Tanjung, Abrar. 2012. Analisis Sistem Distribusi 20 kV Untuk Memperbaiki Kinerja dan Keandalan Sistem Distribusi Menggunakan Electrical Transient Analisys Program. Skripsi. Pekan Baru: Univ. Lancang Kuning.

[8] (2017) kmi. [Online]. Available: www.kmi.co.id standart specification: IEC 60202-1 